Résumés des conférences et travaux

\title{
Sudarabique et ouest-sémitique
}

\section{François Bron}

\section{OpenEdition \\ Journals}

Édition électronique

URL : https://journals.openedition.org/ashp/1135

DOI : $10.4000 /$ ashp. 1135

ISSN : 1969-6310

Éditeur

Publications de l'École Pratique des Hautes Études

Édition imprimée

Date de publication : 1 octobre 2011

Pagination : 26-28

ISSN : 0766-0677

Référence électronique

François Bron, «Sudarabique et ouest-sémitique », Annuaire de l'École pratique des hautes études (EPHE), Section des sciences historiques et philologiques [En ligne], 142 | 2011, mis en ligne le 23 septembre 2011, consulté le 06 juillet 2021. URL : http://journals.openedition.org/ashp/1135 ; DOI https://doi.org/10.4000/ashp.1135 


\title{
SUDARABIQUE ET OUEST-SÉMITIQUE
}

\author{
Directeur d'études : M. François BRoN
}

Programme de l'année 2009-2010 : I. Inscriptions puniques et néo-puniques. — II. Inscriptions sudarabiques du Jawf.

\section{Inscriptions puniques et néo-puniques}

On a poursuivi cette année l'étude d'un certain nombre d'inscriptions néopuniques, à partir du récent manuel de K. Jongeling, Handbook of Neo-Punic Inscriptions (Tübingen 2008). On a revu tout d'abord deux inscriptions de Mididi, Hr. Meded N 27 et 28, grâce aux excellentes photographies publiées par A. Ferjaoui dans le Bulletin des travaux de l'Institut d'archéologie et d'art de Tunis, fasc. 3 (1989), p. 55-61. On a montré ensuite que Hr. Sidi Khalifat N 1 = NP 12 est en réalité d'origine inconnue, même si elle a été republiée par J. Février dans un article où il traite aussi d'une inscription de Pheradi Maius (Karthago, 10, 1959-1960, p. 61-66). Parmi les inscriptions d'origine inconnue, Tunisia OU N 4 = NP 76 est actuellement conservée à La Vallette et a été réétudiée par M.-G. Amadasi Guzzo dans Vicino Oriente, 6 (1986), p. 184-187. On a revu ensuite quelques inscriptions de Constantine, N 28, 42, 44, 67, 69, puis deux inscriptions de Guelma conservées au musée du Louvre, N $20=$ $\mathrm{AO} 5288$, où le nom de l'auteur est à lire $R w m^{\prime} n$ ' = Romanus, avec Chabot, et $\mathrm{N} 7=$ AO 5112. Enfin, les inscriptions de Kheneg = Tiddis ont été étudiées par J. Février et A. Berthier dans le Bulletin d'archéologie algérienne, 6 (1975-1976), p. 67-77.

On a présenté également une inscription provenant de Volubilis, interprétée autrefois par J. Février comme une inscription dédicatoire (IAM 3), et qui vient d'être réétudiée par A. El Khayari dans le Bulletin d'archéologie marocaine, 21 (2009), p. 115-125. Le savant marocain a grandement amélioré la lecture de Février : il a montré qu'il s'agit en fait d'une inscription funéraire et a pu déchiffrer la locution $r s^{2} t n$ ' $m t$, " vieillesse heureuse ", qui vient confirmer l'interprétation que j'avais proposée autrefois d'un passage des inscriptions phéniciennes de Karatepe (AION, 35, 1975, p. 545-546).

On a relu deux inscriptions particulièrement difficiles de Carthage, l'inscription de Milkpilles (CIS 6000 bis) et l'inscription dite « urbanistique », dont M. Sznycer a proposé récemment une nouvelle interprétation (Semitica, 51, 2001 [2003], p. 31-55).

On a consacré enfin près d'une dizaine d'heures à revoir un article de P. Filigheddu, Die Ortsnamen des Mittelmeerraums in der phönizischen und punischen Überlieferung, $U F, 38$ (2006), p. 149-265, tiré d'une thèse soutenue à l'université de Tübingen, en se limitant aux toponymes provenant d'Afrique du Nord. Ce travail, très complet et qui s'appuie sur une abondante bibliographie (22 pages), souffre cependant de nombreux et regrettables défauts, en particulier d'une absence flagrante de sens critique et aussi de la volonté d'identifier à tout prix les toponymes, souvent à partir de vagues assonances avec des noms de lieu modernes. 


\section{Inscriptions sudarabiques du Jawf}

Les conférences de cette année ont été consacrées entièrement à l'étude d'inscriptions inédites, provenant du pillage des sites antiques du Yémen et parvenues sur le marché des antiquités. On sait depuis longtemps que les sites du Jawf, le plus septentrional des grands $w \bar{a} d \bar{l}$ du Yémen, font l'objet d'une exploitation impitoyable par les habitants locaux. On a pu se rendre compte qu'il en va de même du wādī Hạāîb, situé à l'ouest du wādī Bayḥān, qui faisait partie du royaume de Qatabān.

En commençant par le Jawf, on a vu tout d'abord deux pièces provenant de Haram (l'antique $\mathrm{Hrmm}$ ) : une table à libations en calcaire, ornée de cinq têtes de bouquetins et dédiée à 'Athtar Ba'sān, dont on sait maintenant qu'il s'agit d'une déesse. Une table à libations toute semblable, mais dédiée à Matabnatịān, a été publiée récemment par S. A. Tairan (Adumatu, 14, 2006, p. 7-26). L'autre pièce est une plaque en albâtre encadrée de deux rangées de cinq ibex couchés et surmontée de têtes d'antilopes. Ce type de décor est bien connu par de nombreuses dédicaces provenant de divers temples du Jawf ou de Mārib. L'inscription ne comporte qu'une seule ligne. Elle est dédiée à un dieu Yada', qui doit être une forme abrégée de Yada 'sumhū, l'une des divinités caractéristiques de Haram. D'après la graphie, ces deux pièces remontent à la période la plus ancienne de la civilisation sudarabique, peut-être $\mathrm{VIII}^{\mathrm{e}}$ siècle avant notre ère pour la première, $\mathrm{VII}^{\mathrm{e}}$ pour la seconde.

D'al-Bayḍā', l'antique Nšqm, provient une grande stèle en calcaire, dédiée au dieu national sabéen Almaqah et datée par la mention d'un roi de Saba' et dhū-Raydān du troisième quart du $\mathrm{III}^{\mathrm{e}}$ siècle de notre ère. Outre quelques nouveautés lexicographiques, cette inscription nous livre des détails inédits sur les guerres entre le royaume de Saba' et celui de Haḍramawt à cette époque.

D'as-Sawdā', l'antique $N s ̌ n$, provient une dédicace au dieu local Aranyada ', datée de la même époque que la précédente.

On a vu enfin une stèle, dont l'origine exacte n'est pas connue, mais dont le texte rappelle de près les stèles de Jar al-Labba, copiées par Halévy en 1870 et dont l'interprétation reste controversée.

On est passé ensuite aux inscriptions qatabanites : tout d'abord une base de stèle quadrangulaire, dédiée à une déesse $\underline{d} t$ - '$^{\prime} d h n m$, connue jusqu'ici uniquement comme épithète de la déesse dhāt-Ḥamīm. Le lieu d'origine de ce petit monument est incertain, alors que les suivants proviennent très vraisemblablement du site d'al- 'Adī, dans le wādī Ḥarīb, site qui n’a encore jamais été décrit par un archéologue.

On a vu ainsi deux dédicaces à Ḥawkam Nabaț, qui font suite à celles que j'ai publiées récemment dans la revue Orientalia. L'une est une plaque de bronze, l'autre est gravée sur un bloc de calcaire.

Une autre inscription gravée sur bronze constitue peut-être la face antérieure d'un autel; elle est dédiée à une série de divinités, 'Athtar, seigneur de Bana', 'Amm, Hawkam et les dieux du temple Labakh.

Enfin, une grande stèle de calcaire est dédiée à la déesse qatabanite dhātȘannatum.

Ces diverses inscriptions se caractèrisent par la mention du lignage Barnațum ou de la tribu Bakīlum dhū-Maryamatum, ce qui laisse supposer une origine commune. On 
peut en déduire que ce site d'al- 'Adī était un centre religieux important, comportant au moins trois temples.

En fin d'année, on a commencé l'étude d'une grande inscription rupestre, découverte en 1997 et restée inédite depuis lors, dont le directeur d'études prépare la publication, en collaboration avec I. Gajda. Elle date de la fin du $\mathrm{II}^{\mathrm{e}}$ siècle de notre ère et émane de vassaux de la tribu de Maḍhị. Ce travail sera poursuivi l'année prochaine. 